\title{
BMJ Open Interventions to delay functional decline in people with dementia: a systematic review of systematic reviews
}

\author{
Kate Laver, ${ }^{1}$ Suzanne Dyer, ${ }^{1}$ Craig Whitehead, ${ }^{1}$ Lindy Clemson, ${ }^{2}$ Maria Crotty ${ }^{1}$
}

To cite: Laver K, Dyer S, Whitehead $\mathrm{C}$, et al. Interventions to delay functional decline in people with dementia: a systematic review of systematic reviews. BMJ Open 2016;6:e010767. doi:10.1136/bmjopen-2015010767

- Prepublication history and additional material is available. To view please visit the journal (http://dx.doi.org/ 10.1136/bmjopen-2015010767).

Received 6 December 2015 Revised 16 February 2016 Accepted 29 February 2016

CrossMark

\section{${ }^{1}$ Department of \\ Rehabilitation, Aged and Extended Care, Flinders University, Adelaide, South Australia, Australia ${ }^{2}$ Ageing, Work and Health Research Unit, University of Sydney, Sydney, New South Wales, Australia}

Correspondence to Dr Kate Laver;

Kate.Laver@flinders.edu.au

\section{ABSTRACT}

Objective: To summarise existing systematic reviews that assess the effects of non-pharmacological, pharmacological and alternative therapies on activities of daily living (ADL) function in people with dementia. Design: Overview of systematic reviews.

Methods: A systematic search in the Cochrane Database of Systematic Reviews, DARE, Medline, EMBASE and Psyclnfo in April 2015. Systematic reviews of randomised controlled trials conducted in people with Alzheimer's disease or dementia measuring the impact on ADL function were included. Methodological quality of the systematic reviews was independently assessed by two authors using the AMSTAR tool. The quality of evidence of the primary studies for each intervention was assessed using GRADE.

Results: A total of 23 systematic reviews were included in the overview. The quality of the reviews varied; however most $(65 \%)$ scored $8 / 11$ or more on the AMSTAR tool, indicating high quality. Interventions that were reported to be effective in minimising decline in ADL function were: exercise (6 studies, 289 participants, standardised mean difference (SMD) 0.68 , $95 \% \mathrm{Cl} 0.08$ to 1.27 ; GRADE: low), dyadic interventions (8 studies, 988 participants, SMD 0.37, $95 \% \mathrm{Cl} 0.05$ to 0.69 ; GRADE: low) acetylcholinesterase inhibitors and memantine (12 studies, 4661 participants, donepezil $10 \mathrm{mg} \mathrm{SMD} 0.18,95 \% \mathrm{Cl} 0.03$ to 0.32 ; GRADE: moderate), selegiline (7 studies, 810 participants, SMD $0.27,95 \% \mathrm{Cl} 0.13$ to 0.41 ; GRADE: low), huperzine A (2 studies, 70 participants, SMD $1.48,95 \% \mathrm{Cl} 0.95$ to 2.02; GRADE: very low) and Ginkgo biloba (7 studies, 2530 participants, SMD 0.36, $95 \% \mathrm{Cl} 0.28$ to 0.44 ; GRADE: very low).

Conclusions: Healthcare professionals should ensure that people with dementia are encouraged to exercise and that primary carers are trained and supported to provide safe and effective care for the person with dementia. Acetylcholinesterase inhibitors or memantine should be trialled unless contraindicated.

Trial registration number: CRD42015020179.

\section{INTRODUCTION}

Dementia affects approximately 35.6 million people worldwide. ${ }^{1}$ This figure is expected to nearly double every 20 years due to
Strengths and limitations of this study

- This overview examines the efficacy for a number of different treatment approaches in delaying functional decline.

- The effect sizes of the different treatment approaches are compared providing clinicians and policymakers with information regarding treatments that should be prioritised.

- The quality of the included reviews is appraised using AMSTAR and the quality of evidence for each intervention is appraised using GRADE.

- There is a debate regarding the most appropriate methodology for conducting overviews including how authors should capture the most recent evidence and avoid including overlapping reviews.

population ageing. ${ }^{2}$ It is one of the leading causes of mortality and morbidity, particularly in people aged 60 years or over in which it affects approximately $5-7 \%$ of the population. ${ }^{1}$

The trajectory of dementia is associated with gradual functional decline whereby the person with dementia requires more assistance to manage activities over time due to cognitive and physical impairment. Functional decline is associated with reduced quality of life in people with dementia ${ }^{3}$ and increased care costs. ${ }^{4}$ It is also associated with increased need for informal care and can increase the carer burden, particularly when the rate of decline is rapid..$^{5}$

While dementia is a terminal condition, the length of time between diagnosis and death can be many years. ${ }^{6}$ Therefore, one of the goals of treatment, particularly in the earlier stages of the disease, is to promote independence and reduce functional decline. ${ }^{7}$ Consumers have called for a greater focus on rehabilitation and restorative care in order to maximise the quality of life. ${ }^{8}$

There are a number of intervention approaches that have been trialled to manage the symptoms of dementia including pharmacological approaches (such as acetylcholinesterase 
inhibitors) and non-pharmacological approaches (such as exercise). The vast amount of research literature means that it can be difficult for health professionals to keep themselves up to date in understanding which interventions are thought to be effective overall and the relative efficacy of different intervention approaches. Systematic reviews of systematic reviews (overviews) are useful in that they examine the effectiveness of a number of different interventions for a particular health condition. ${ }^{9}$ Systematic reviews do not traditionally attempt to do this due to time and resources involved in conducting such a review.

The aim of this review was to summarise systematic reviews that assess the effects of intervention for functional decline in people with dementia.

\section{METHODS}

An a priori review protocol was developed and registered on the PROSPERO International prospective register of systematic reviews (http://www.crd.york.ac.uk/PROSPERO; registration number CRD42015020179). The protocol provides full details of the methods used. There were no changes made to the protocol during the review.

\section{Inclusion and exclusion criteria \\ Types of studies}

This overview included the most recent and comprehensive systematic reviews. Systematic reviews were defined as 'a review of the evidence on a clearly formulated question that uses systematic and explicit methods to identify, select and critically appraise relevant primary research, and to extract and analyse data from the studies that are included in the review'. ${ }^{10}$ In order to be eligible, the systematic review must have included randomised controlled trials (RCTs). Cochrane Reviews and systematic reviews published in other peer-reviewed journals were eligible. Systematic reviews that overlapped with the most up to date and comprehensive review in terms of the intervention approach were excluded to avoid double counting of studies where possible. Reviews published in non-English languages were excluded.

\section{Population}

Reviews which included populations of people with a diagnosis of dementia (any cause) or Alzheimer's disease were included. Reviews were excluded if they included people with non-Alzheimer's dementia only (eg, people with vascular dementia). Studies conducted in any setting, whether community or residential, were included.

\section{Intervention and comparison}

All interventions intended to treat or manage the symptoms of dementia were eligible; this included nonpharmacological interventions (such as exercise, counselling or education), pharmacological interventions (such as acetylcholinesterase inhibitors) and alternative therapies (such as Ginkgo biloba). Reviews including RCTs which compared the intervention to usual care, placebo or another form of intervention were included.

\section{Outcome}

The overview included reviews where performance of global activities of daily living (ADL) was reported as a primary or secondary outcome. ADL whether measured by observation, self-report or proxy report or tools such as the Functional Independence Measure, Barthel Index, Alzheimer's Disease Co-operative Study -ADL Inventory, Disability Assessment for Dementia or Cleveland Scale for ADL were eligible.

\section{Search methods for identification of reviews}

Searches were conducted in the Cochrane Database of Systematic Reviews Dementia and Cognitive Improvement Group domain, Cochrane DARE, Medline, EMBASE and PsycINFO in April 2015. The Medline search strategy is attached as an online supplementary file and was adapted for the other databases. The search strategy was formulated including the dementia search string used by the Cochrane Dementia and Cognitive Improvement Group for dementia.

\section{Data collection and analysis}

Selection of reviews

One author (KL) conducted the searches and assessed all retrieved citations meeting the inclusion criteria on the basis of title and abstract. A second author (SD) independently reviewed $10 \%$ of the excluded articles. Potentially eligible reviews were reviewed in full text. Two authors (KL and SD) independently assessed all articles obtained in full text. A third author was consulted in cases of disagreement. Eligible reviews were classified based on intervention approach (eg, exercise) and discussion occurred regarding the most appropriate review to include (based on recency and quality). We used methods consistent with the Cochrane Handbook; we did not repeat the searches, determine eligibility, assess risk of bias, conduct additional meta-analysis or aim to identify any additional studies. ${ }^{9}$ Thus, we accepted included reviews as being 'complete' and did not check other reviews for missing studies.

\section{Data extraction and management}

One author (KL) extracted the data which was checked by a second researcher. Disagreements were resolved by a third author. A data collection form was developed and tested prior to starting the review. Fields extracted included review details (author, title, year), review aims, inclusion criteria, date of last search and data from included RCTs that provided a comparison to usual care, placebo or another form of treatment. If the review included data from RCTs and other study designs, we extracted the data for the RCTs only. Where RCTs and quasi-RCTs were included, we extracted only the RCT data when possible (ie, when individually 
reported). We extracted details on the number of RCTs included in the review, population size and characteristics, intervention and comparator characteristics and outcomes (on an individual study basis or pooled values as reported in the included review). Authors of the included reviews were not contacted for further information.

\section{Assessment of quality of included reviews}

Two people (KL and a second researcher) independently assessed the methodological quality of the included reviews using the AMSTAR checklist. ${ }^{11}$ The AMSTAR checklist includes a number of criteria which reflect whether the review was guided by a protocol, whether there was duplicate study selection and data extraction, the comprehensiveness of the search, inclusion of grey literature, use of quality assessment, appropriateness of data synthesis and documentation of conflict of interest. Disagreements regarding AMSTAR score were resolved by discussion or a decision made by a third author.

\section{Assessment of quality of the body of evidence for each intervention}

GRADE was used to rate the quality of the evidence for each intervention. ${ }^{12}$ The GRADE level was determined based on information provided in the systematic review. The level considers the risk of bias of included studies, indirectness of evidence, inconsistency of results (heterogeneity), imprecision of results and possibility of publication bias. ${ }^{12}$

\section{Data synthesis}

Data was synthesised in tables and a narrative synthesis was used to provide a summary of results. Effect sizes were also expressed graphically using standardised mean difference. Where meta-analysis had already been conducted within the review, we used the meta-analysis performed by the authors. We did not conduct additional meta-analyses, however where the results were presented as mean difference, we calculated the standardised mean difference to enable comparison of effect sizes across reviews.

\section{RESULTS}

The study selection process is presented in figure 1 (PRISMA). There were 23 systematic reviews meeting all inclusion criteria and included in this overview. ${ }^{13-35}$ An additional 10 reviews were identified that listed ADL as an outcome of interest; however the reviews failed to identify any applicable studies. These reviews were for socially assistive robots, animal-assisted therapy, transcutaneous electrical nerve stimulation, social support groups for the person with dementia, naftidrofuryl, respite care, smart home technologies, metal protein-attenuating compounds, ibuprofen and educational interventions for the person with dementia. ${ }^{36-45}$ One review evaluated the efficacy of metrifonate, however identified serious harms associated with use; metrifonate was since withdrawn from the market. ${ }^{46}$ These reviews are not discussed further. In most cases, the most recent comprehensive review (ie, dementia or Alzheimer's disease) reporting ADL outcomes was deemed as being of acceptable quality for inclusion. There were two intervention categories where this was not the case. We excluded two reviews of cognitive rehabilitation which were published more recently than the included Cochrane Review but involved a search date that was not as recent as the included review. ${ }^{47}$ We also excluded two systematic reviews of exercise that were published more recently than the included review. One of the excluded reviews was of lower quality than the Cochrane Review and included non-randomised trials, but involved a search date that was 6 months more recent. ${ }^{49} \mathrm{~A}$ second review included studies where exercise was included as one component of a multifactorial programme. $^{50}$

\section{Characteristics of the included reviews}

Characteristics of the included reviews are summarised in table 1. Fifteen $(65 \%)$ of the reviews were Cochrane Reviews. Eleven reviews addressed non-pharmacological approaches. These were cognitive training, cognitive stimulation therapy, light therapy, exercise, aromatherapy, nutritional supplementation, validation therapy, psychological treatment, case management, music therapy and intervention for the person with dementia and carer dyad. Eight reviews addressed pharmacological approaches. These were acetylcholinesterase inhibitors and memantine, pharmacotherapies to improve sleep, latrepirdine, melatonin, statins, selegiline, lecithin and nimodipine. Four reviews addressed alternative therapies. These were vitamin B supplementation, G. biloba, huperzine $\mathrm{A}$ and acupuncture.

Most $(65 \%)$ of the reviews included people with any form of dementia. The remaining reviews included only people with Alzheimer's disease. The mean age of participants in all reviews was people in their $70 \mathrm{~s}$ or $80 \mathrm{~s}$ with the exception of the G. biloba and huperzine A reviews which involved younger participants. Most participants had mild-to-moderate severity dementia, although some reviews of pharmacological interventions (eg, acetylcholinesterase inhibitors) included a large number of participants with severe dementia. The duration of different interventions varied from days to months and a large number of outcome assessment measures were used to assess ADL function.

\section{Methodological quality of included reviews}

The quality of the included review reflects the rigour and transparency of the review team rather than the quality of evidence for the intervention approach. Most of the reviews $(65 \%)$ were of high quality (scores $\geq 8$ / 11) as assessed using the AMSTAR tool (table 1). High-quality reviews were for latrepirdine, light therapy, exercise, aromatherapy, pharmacotherapies for sleep, 

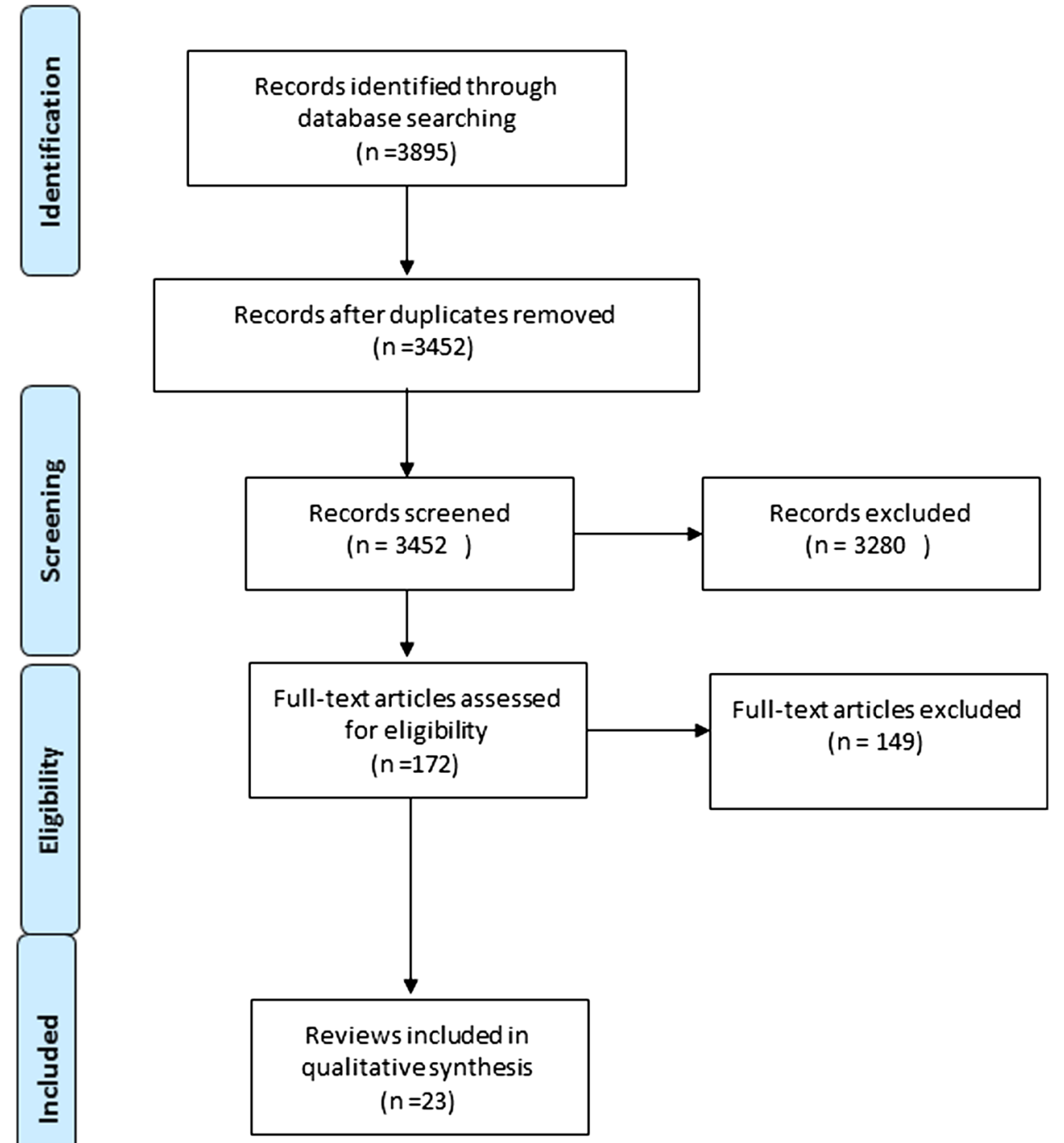

Figure 1 PRISMA 2009 flow diagram.

case management, cognitive stimulation therapy, huperzine A, lecithin, selegiline and nimodipine. However, there were also two lower quality reviews (scoring 5 or less on AMSTAR). Low-quality reviews were for G. biloba and dyadic interventions.

\section{Quality of evidence in included reviews}

While the authors of this overview did not reassess the risk of bias of primary studies included in the reviews, it was necessary to examine the quality of these studies as determined by the original review authors to determine the overall quality of the evidence using GRADE. It can be seen from figure 2 that studies in most of the reviews had a risk of bias resulting in downgrading of the quality overall.

The quality of evidence for all non-pharmacological interventions was low with the exception of nutritional supplementation for which the evidence base was of moderate quality. The quality of evidence for pharmacological interventions ranged from low (latrepirdine) to high (statins). In contrast, alternative therapies had very low (huperzine A, G. biloba, acupuncture)-to-moderate (vitamins B) evidence.

\section{EFFECT OF INTERVENTIONS}

Effects are presented in table 2. Non-pharmacological interventions: two non-pharmacological interventions demonstrated a significant effect in reducing to functional decline in people with dementia. Exercise had a large magnitude of effect (six studies, 289 participants, SMD $0.69,95 \%$ CI 0.08 to 1.27 ) however the quality of evidence was low due to a risk of bias in some studies and the limited number of participants in the analysis. Dyadic interventions, in which the therapeutic intervention aims to engage the person with dementia and their carer in maximising quality of life (utilising interventions, defined broadly as psychosocial but which also included meaningful activities, daily living activities and 


\begin{tabular}{|c|c|c|c|c|c|c|}
\hline Review & $\begin{array}{l}\text { Date of } \\
\text { search }\end{array}$ & Population included in the review & $\begin{array}{l}\text { Intervention addressed } \\
\text { in the review }\end{array}$ & $\begin{array}{l}\text { Comparison } \\
\text { intervention }\end{array}$ & Measures of ADL & $\begin{array}{l}\text { Quality of the } \\
\text { review } \\
\text { (AMSTAR) }\end{array}$ \\
\hline \multicolumn{7}{|c|}{ Non-pharmacological interventions } \\
\hline Forbes & Oct 2013 & $\begin{array}{l}\text { Older people (over } 65 \text { years of age) and } \\
\text { diagnosed as having dementia using } \\
\text { accepted criteria } \\
\text { Mean age ranged from } 73 \text { to } 89 \\
\text { Baseline MMSE ranged from } 8 \text { to } 23\end{array}$ & Exercise programmes & $\begin{array}{l}\text { Usual care or social } \\
\text { contact/activities }\end{array}$ & $\begin{array}{l}\text { Barthel ADL index, Katz } \\
\text { Index of ADLs, Changes } \\
\text { in Advanced Dementia } \\
\text { Scale }\end{array}$ & $10 / 11$ \\
\hline Van’t Leven & Jan 2012 & $\begin{array}{l}\text { Older people (aged } 65 \text { years or more) } \\
\text { with a diagnosis of dementia. } \\
\text { Participants were included if they were } \\
\text { living in informal carers in the community } \\
\text { and excluded if they were living in } \\
\text { residential care settings. } \\
\text { Mean age not reported though inclusion } \\
\text { criteria states }>65 \text {. } \\
\text { Participants had mild-to-moderate } \\
\text { severity dementia. }\end{array}$ & Dyadic interventions & Not specified & $\begin{array}{l}\text { Barthel Index } \\
\text { AMPS } \\
\text { IDDD } \\
\text { Functional Dependence } \\
\text { Scale }\end{array}$ & $5 / 11$ \\
\hline Neal & Aug 2005 & $\begin{array}{l}\text { Older people (aged over } 65 \text { years) } \\
\text { diagnosed with Alzheimer's disease, } \\
\text { dementia or other forms of cognitive } \\
\text { impairment } \\
\text { Nursing home residents with BPSD. } \\
\text { Mean age } 88 \text {. }\end{array}$ & $\begin{array}{l}\text { Validation therapy (affirming } \\
\text { the person's beliefs and } \\
\text { experiences) }\end{array}$ & $\begin{array}{l}\text { Usual care or } \\
\text { alternative } \\
\text { intervention (eg, } \\
\text { social contact group) }\end{array}$ & Not specified & $7 / 11$ \\
\hline Orgeta & Jan 2013 & $\begin{array}{l}\text { Older people (aged over } 65 \text { years) } \\
\text { diagnosed with Alzheimer's disease or } \\
\text { other forms of dementia } \\
\text { Mean age range } 75-76 \\
\text { Mean MMSE range } 22-24\end{array}$ & $\begin{array}{l}\text { Psychological treatments for } \\
\text { depression and anxiety }\end{array}$ & $\begin{array}{l}\text { Usual care or } \\
\text { non-specific } \\
\text { psychosocial therapy }\end{array}$ & $\begin{array}{l}\text { Bristol Activities of Daily } \\
\text { Living } \\
\text { ADSC-ADL }\end{array}$ & $8 / 11$ \\
\hline Reilly & March 2014 & $\begin{array}{l}\text { Diagnosis of dementia of any subtype } \\
\text { and of any severity } \\
\text { Mean age range } 78-80 \\
\text { Most participants had mild-to-moderate } \\
\text { severity dementia }\end{array}$ & Case management & $\begin{array}{l}\text { Usual care or } \\
\text { alternative } \\
\text { intervention }\end{array}$ & $\begin{array}{l}\text { Everyday Abilities Scale } \\
\text { for India } \\
\text { ADCS-ADL } \\
\text { Barthel Index }\end{array}$ & $9 / 11$ \\
\hline Ueda & Feb 2011 & $\begin{array}{l}\text { Diagnosis of dementia of any type } \\
\text { according to accepted criteria. } \\
\text { Mean age } 83 \\
\text { Severity not reported }\end{array}$ & Music therapy & Not specified & Barthel Index & $7 / 11$ \\
\hline Woods & Dec 2011 & $\begin{array}{l}\text { Diagnosis of dementia or any subtype } \\
\text { and of any severity. } \\
\text { Mean age range } 74-85 \\
\text { Mean MMSE range } 20-22\end{array}$ & $\begin{array}{l}\text { Cognitive stimulation } \\
\text { intervention targeting } \\
\text { cognitive and social } \\
\text { functioning }\end{array}$ & $\begin{array}{l}\text { No treatment, usual } \\
\text { care or placebo }\end{array}$ & $\begin{array}{l}\text { Barthel Index } \\
\text { IADL } \\
\text { Stewart ADL Scale }\end{array}$ & $10 / 11$ \\
\hline
\end{tabular}

Baseline MMSE ranged from 8 to 23

living in informal carers in the community

settings.

criteria states $>65$.

Participants had mild-to-moderate

dementia or other forms of cognitive

impairment

age 88.

Mean age range $75-76$

and of any severity

Mean age range $78-80$

Mean age 83

Mean MMSE range 20-22 


\begin{tabular}{|c|c|c|c|c|c|c|}
\hline Review & $\begin{array}{l}\text { Date of } \\
\text { search }\end{array}$ & Population included in the review & $\begin{array}{l}\text { Intervention addressed } \\
\text { in the review }\end{array}$ & $\begin{array}{l}\text { Comparison } \\
\text { intervention }\end{array}$ & Measures of ADL & $\begin{array}{l}\text { Quality of the } \\
\text { review } \\
\text { (AMSTAR) }\end{array}$ \\
\hline McCleery & March 2013 & $\begin{array}{l}\text { People who had both: } \\
\text { A. Alzheimer's disease diagnosed using } \\
\text { any well-validated criteria, such as } \\
\text { DSM, at the time of the study, and } \\
\text { B. a sleep problem diagnosed on the } \\
\text { basis of subjective or objective } \\
\text { measures } \\
\text { Mean age ranged } 77-81 \\
\text { Mean MMSE range } 11-14\end{array}$ & Pharmacotherapies for sleep & Placebo & Katz Index & $10 / 11$ \\
\hline McGuinness & Jan 2014 & $\begin{array}{l}\text { Patients with a diagnosis of probable or } \\
\text { possible AD according to accepted } \\
\text { criteria. } \\
\text { Mean age } 74-79 \\
\text { Mild-to-moderate severity dementia }\end{array}$ & Statins & Placebo & $\begin{array}{l}\text { ADCS-ADL } \\
\text { ADFACS }\end{array}$ & $7 / 11$ \\
\hline Birks & July 2002 & $\begin{array}{l}\text { Diagnosis of probable Alzheimer's } \\
\text { disease } \\
\text { Mean age ranged from } 70 \text { to } 83 \text { in the } \\
\text { studies reporting ADL outcomes } \\
\text { Studies included people with } \\
\text { mild-to-moderate dementia }\end{array}$ & Selegeline & Placebo & Unclear & $9 / 11$ \\
\hline Birks & March 2010 & $\begin{array}{l}\text { People with unclassified dementia, } \\
\text { Alzheimer's disease, vascular dementia } \\
\text { or mixed dementia } \\
\text { Mean age ranged from } 74 \text { to } 80 \text { in the } \\
\text { studies reporting ADL outcomes } \\
\text { Studies included people with } \\
\text { mild-to-moderate dementia }\end{array}$ & Nimodipine & Placebo & Unclear & $9 / 11$ \\
\hline Higgins & May 2004 & $\begin{array}{l}\text { Diagnosis of dementia of any type } \\
\text { Mean age } 74 \text { years } \\
\text { Mild-to-moderate severity }\end{array}$ & Lecithin & Placebo & PADL Scale & $9 / 11$ \\
\hline \multicolumn{7}{|c|}{ Alternative therapies } \\
\hline Yang & June 2013 & $\begin{array}{l}\text { Diagnosis of Alzheimer's disease. } \\
\text { People with other forms of dementia } \\
\text { were excluded. } \\
\text { All studies but one conducted in China } \\
\text { Age range } 50-85 \\
\text { Details regarding severity of dementia } \\
\text { not reported }\end{array}$ & Huperzine A & $\begin{array}{l}\text { No treatment, usual } \\
\text { care or placebo. }\end{array}$ & $\begin{array}{l}\text { Activities of Daily Living } \\
\text { Scale } \\
\text { ADCS-ADL }\end{array}$ & $9 / 11$ \\
\hline Tan & March 2014 & $\begin{array}{l}\text { Diagnosis of dementia of any type or } \\
\text { people with mild cognitive impairment }\end{array}$ & Gingko biloba & Placebo & $\begin{array}{l}\text { ADL-IS } \\
\text { GBS-ADL }\end{array}$ & $3 / 11$ \\
\hline
\end{tabular}

eople who had both:

diagnosed using

problem diagnosed on the

with a diagnosis of probable or

criteria.

Diagnosis of probable Alzheimer's

disease

studies reporting ADL outcomes

Studies included people with

Alzheimer's disease, vascular dementia

studies reporting ADL outcomes

Diagnosis of dementia of any type

Mean age 74 years 


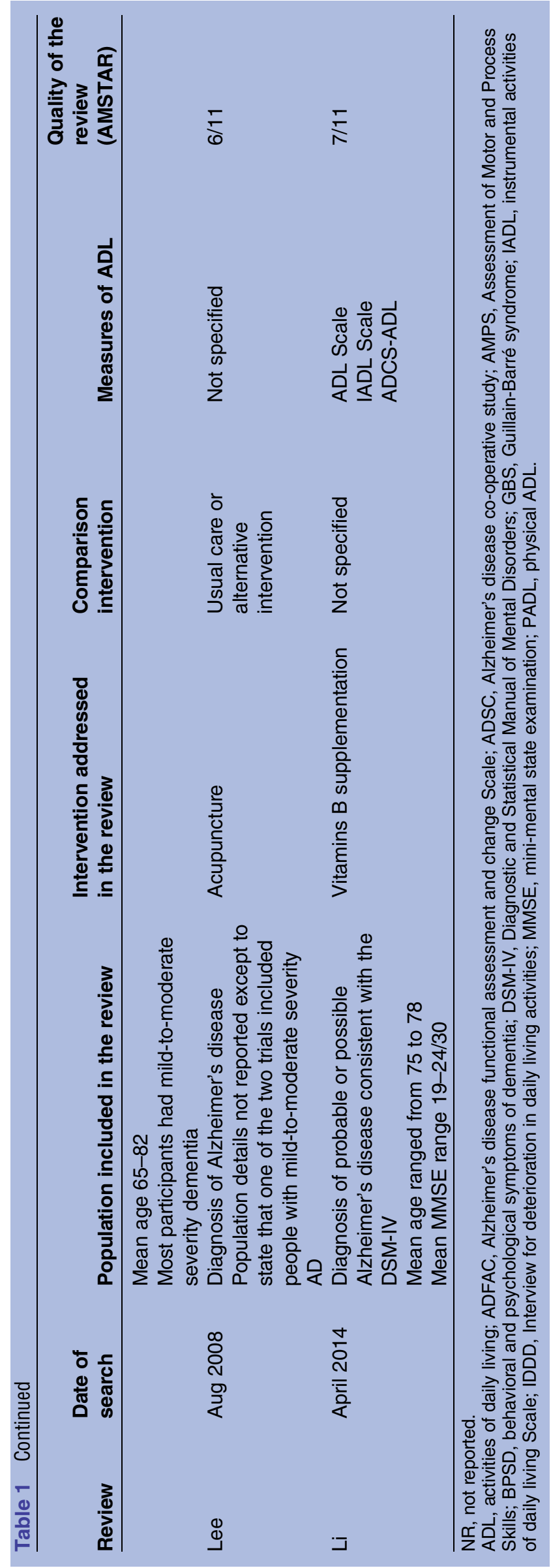

environmental adaptations) were also associated with a significant positive effect on ADL (eight studies, 988 participants, SMD $0.37,95 \%$ CI 0.05 to 0.69). Again, a number of studies were at risk of bias and there were mixed findings among studies. There was insufficient evidence to conclude whether or not the other intervention approaches were effective due to the small number of studies and the low quality of evidence.

Pharmacological interventions: two pharmacological interventions demonstrated a significant effect on ADL function. The use of acetylcholinesterase inhibitors or memantine was associated with a small but statistically significant effect on function (12 studies, 4661 participants, donepezil $5 \mathrm{mg}$ SMD 0.18 , 95\% CI 0.10 to 0.46 ; donepezil $10 \mathrm{mg}$ SMD 0.18, 95\% CI 0.03 to 0.32; galantamine $24 \mathrm{mg}$ SMD 0.15 , 95\% CI 0.04 to 0.25 ; rivastigmine $12 \mathrm{mg}$ SMD $0.19,95 \%$ CI 0.02 to 0.36 ). Overall, the evidence for acetylcholinesterase inhibitors and memantine was of moderate quality. Effect sizes varied slightly according to the specific agent and dose used, although the effect size was consistently small. Selegiline was also found to have a small statistically significant effect on ADL function at 8-17-week follow-up (seven studies, 810 participants, SMD $0.27,95 \%$ CI 0.13 to $0.41)$. Studies were at risk of bias and there were mixed findings between studies hence the quality of evidence was low.

Alternative therapies: two of the alternative therapies were reported to significantly improve ADL function. Huperzine A was reported to be effective although this was based on only two studies (two studies, 70 participants, SMD 1.48, 95\% CI 0.95 to 2.02). Furthermore, the studies included in the review were at a high risk of bias due to unclear allocation concealment, possible selective reporting and risk of incomplete outcome data in both of the studies, and possible non-blinded outcome assessor in one of the studies. In addition, the outcome measure used in the pooled analysis in the review is not clearly reported. Overall, the quality of evidence for huperzine A was considered very low. G. biloba was also reported to be effective in the included systematic review, however it was also associated with very lowlevel evidence; the quality of the systematic review (AMSTAR=3/11) and the included studies was low (seven studies, 2530 participants, SMD $0.36,95 \%$ CI 0.28 to 0.44). Furthermore, although there were seven included studies in the review, the findings were inconsistent between the studies.

\section{DISCUSSION}

This overview identified 23 systematic reviews (including 84 studies reporting on ADL performance outcomes). These reviews addressed a range of different interventions that may be considered for use in people with dementia. Of the 23 interventions reviewed, only six were reported to be successful in reducing functional decline. Acetylcholinesterase inhibitors and memantine, 
Number of studies

\begin{tabular}{|c|c|c|c|c|}
\hline \multirow[b]{2}{*}{ Intervention approach } & \multicolumn{2}{|c|}{ Number of studies } & \multicolumn{2}{|c|}{ Quality of the eviden } \\
\hline & ticipants) & $\operatorname{SMD}(95 \% \mathrm{Cl})$ & $\operatorname{SMD}(95 \% \mathrm{Cl})$ & (GRADE) \\
\hline \multicolumn{5}{|l|}{ Nonpharmacological approach } \\
\hline Exercise & $6(289)$ & $\longrightarrow$ & $0.68(0.08$ to 1.27$)$ & Low \\
\hline Dyadic intervention & $8(988)$ & $\longrightarrow$ & $0.37(0.05$ to 0.69$)$ & Low \\
\hline Psychological treatments & $2(313)$ & $\rightarrow$ & $-0.13(-0.35$ to 0.09$)$ & Low \\
\hline Case management & $3(318)$ & 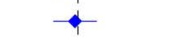 & $-0.03(-0.25$ to 0.19$)$ & Low \\
\hline Music therapy & $6(195)$ & $\rightarrow$ & $0.05(-0.23$ to 0.34$)$ & Low \\
\hline Cognitive stimulation therapy & $4(260)$ & & $0.21(-0.05$ to 0.47$)$ & Low \\
\hline Cognitive training & $4(107)$ & 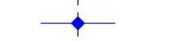 & $0(-0.38$ to 0.38$)$ & Low \\
\hline \multicolumn{5}{|l|}{ Pharmacological approach } \\
\hline Donepezil & $3(733)$ & $\leftarrow$ & $0.18(0.03$ to 0.32$)$ & Moderate \\
\hline Galantamine & $3(1422)$ & $\bullet$ & $0.15(0.04$ to 0.25$)$ & Moderate \\
\hline Rivastigmine & $1(535)$ & $\bullet$ & $0.19(0.02$ to 0.36$)$ & Moderate \\
\hline Memantine & $5(1773)$ & - & $0.11(0.02$ to 0.21$)$ & Moderate \\
\hline Latrepirdine & $3(1243)$ & $\rightarrow$ & $0.06(-0.06$ to 0.17$)$ & Low \\
\hline Melatonin & $1(86)$ & $\bullet 1$ & $-0.15(-0.58$ to 0.27$)$ & Moderate \\
\hline Selegiline & $7(810)$ & $\bullet$ & $0.27(0.13$ to 0.41$)$ & Low \\
\hline Nimodipine & $3(1228)$ & $\leftarrow$ & $0.12(0.00$ to 0.23$)$ & Moderate \\
\hline \multicolumn{5}{|l|}{ Alternative therapies } \\
\hline Huperzine A & $2(70)$ & $i$ & $1.48(0.95$ to 2.02$)$ & Very low \\
\hline Gingko Biloba & $7(2530)$ & $\bullet$ & $0.36(0.28$ to 0.44$)$ & Very low \\
\hline Vitamin B sup & $3(481)$ & $\bullet$ & $0.13(-0.05$ to 0.31$)$ & Moderate \\
\hline
\end{tabular}

$\begin{array}{lllllll}-1.5 & -1 & -0.5 & 0 & 0.5 & 1 & 1.5\end{array}$

Figure 2 The effect of different treatment approaches on activities of daily living function in people with dementia.

pharmacological agents that are widely used in treating dementia, were convincingly demonstrated to improve the ADL (based on moderate quality evidence), although the effect sizes were small. The quality of the evidence was considered low for two nonpharmacological approaches (exercise and dyadic psychosocial interventions), however the effect sizes were small-to-moderate, suggesting that more research is required to confirm effect on ADL. Evidence was very low for the two alternative therapies (huperzine A and G. biloba) indicating that the findings of improving ADL should be interpreted with extreme caution for these therapies. In addition, we found insufficient evidence to conclude that the remaining intervention approaches are ineffective due to the lack of studies examining each approach and poor methodological quality of existing studies. While caution is required, due to the absence of effective treatment options and trajectory of functional decline associated with dementia, it is recommended that after consideration of potential benefits, harms and costs, health professionals consider prescription of acetylcholinesterase inhibitors/memantine as a method of reducing functional decline. Furthermore, the effects of exercise and dyadic interventions are thought to be greater and they are not associated with side effects, therefore these interventions should be routinely recommended for people with dementia.

The magnitude of the effect sizes of the interventions demonstrated to be effective were considered small to moderate. ${ }^{51}$ Thus, while the intervention may significantly improve performance of the ADL, the effect may not be strong enough to impact on outcomes of institutionalisation, carer impact or quality of life. Two recent systematic reviews revealed that only a small number of studies have been shown to improve quality of life for people with dementia. ${ }^{52} 53$ The reviews found that carer interventions and dyadic interventions for people living in private dwellings and cognitive stimulation therapy for people in group homes had the best evidence for positively impacting on quality of life. ${ }^{52}$

The number of studies, particularly of pharmacological agents, that measured the impact on ADL was generally small. Interventional studies in dementia research frequently focus on outcomes of cognitive function as the key symptoms of dementia, particularly in the earlier phases of the condition, are cognitive. However, studies should also examine impact on ADL function as improvements in cognitive function may not translate to gains in ADL performance or other patient-important outcomes such as quality of life. For example, the included review of acetylcholinesterase inhibitors and memantine included 23 studies of which only 12 looked at the effect of the interventions on ADL function. ${ }^{27}$ Similarly, the included review of exercise comprised 16 RCTs; nine of the studies reported cognitive outcomes, whereas only six reported ADL function outcomes despite the expectation that this would be a key expected outcome of any exercise programme. ${ }^{16}$ 
Table 2 Effects of interventions as reported in the included systematic reviews

\begin{tabular}{|c|c|c|c|c|c|}
\hline Intervention and comparison intervention & $\begin{array}{l}\text { Number of participants included in } \\
\text { the meta-analysis (studies) }\end{array}$ & $\begin{array}{l}\text { Measure of } \\
A D L\end{array}$ & $\begin{array}{l}\text { Effect measure (expressed as SMD or } \\
\text { MD) }\end{array}$ & $\begin{array}{l}\text { Statistically } \\
\text { significant }\end{array}$ & $\begin{array}{l}\text { Quality of the } \\
\text { evidence (GRADE) }\end{array}$ \\
\hline \multicolumn{6}{|l|}{ Non-pharmacological interventions } \\
\hline $\begin{array}{l}\text { Exercise programmes vs usual care } \\
\text { (postintervention) }^{16}\end{array}$ & 6 studies (289 participants) & Multiple & SMD 0.68 (0.08 to 1.27$)$ & Yes & $\begin{array}{l}\oplus \oplus \bigcirc \bigcirc \\
\operatorname{Low}^{1 a, 3}\end{array}$ \\
\hline Dyadic interventions vs control $^{30}$ & 8 studies (988 participants) & Multiple & SMD 0.37 (0.05 to 0.69$)$ & Yes & $\begin{array}{l}\oplus \oplus \bigcirc \bigcirc \\
\text { Low }^{1 b, 2}\end{array}$ \\
\hline Validation therapy vs usual care (1 year) ${ }^{24}$ & 1 study (88 participants) & Unclear & $\begin{array}{l}\text { Review stated effect on ADL was not } \\
\text { significant (data not reported) }\end{array}$ & No & $\begin{array}{l}\oplus \oplus \bigcirc \bigcirc \\
\text { Low }^{1 \mathrm{c}, 3}\end{array}$ \\
\hline $\begin{array}{l}\text { Psychological treatments for depression and } \\
\text { anxiety vs usual care (postintervention } \\
(6 \text { weeks } / 8-12 \text { months }))^{25}\end{array}$ & 2 studies (313 participants) & Multiple & SMD $-0.13(-0.35$ to 0.09$)$ & No & $\begin{array}{l}\oplus \oplus{ }^{10} \\
\text { Low }^{16,3}\end{array}$ \\
\hline $\begin{array}{l}\text { Case management vs usual care } \\
(6 \text { months })^{26}\end{array}$ & 3 studies (318 participants) & Multiple & SMD $-0.03(-0.25$ to 0.19$)$ & No & $\begin{array}{l}\oplus \oplus \bigcirc \bigcirc \\
\operatorname{Low}^{1 \mathrm{~d}, 3}\end{array}$ \\
\hline $\begin{array}{l}\text { Music therapy vs control (postintervention) } \\
\mathrm{B}^{29}\end{array}$ & 6 studies (195 participants) & Multiple & SMD 0.05 ( -0.23 to 0.34$)$ & No & $\begin{array}{l}\oplus \oplus \bigcirc \bigcirc \\
\text { Low }^{1 e, 3}\end{array}$ \\
\hline $\begin{array}{l}\text { Cognitive stimulation vs no cognitive } \\
\text { stimulation (postintervention) }\end{array}$ & 4 studies (260 participants) & Multiple & SMD $0.21(-0.05$ to 0.47$)$ & No & $\begin{array}{l}\oplus \oplus \bigcirc \bigcirc \\
\operatorname{Low}^{1,3}\end{array}$ \\
\hline $\begin{array}{l}\text { Cognitive training vs control } \\
\text { (postintervention) })^{13}\end{array}$ & 4 studies (107 participants) & Multiple & SMD $0.00(-0.38$ to 0.38$)$ & No & $\begin{array}{l}\oplus \oplus \bigcirc \bigcirc \\
\text { Low }^{19,3}\end{array}$ \\
\hline Light therapy vs control (at 1 year) ${ }^{15}$ & 1 study (94 participants) & NI-ADLs & $\begin{array}{l}\text { MD }-5.0(-11.16 \text { to } 1.16) \\
\text { Data not available for conversion to } \\
\text { SMD }\end{array}$ & No & $\begin{array}{l}\oplus \oplus \bigcirc \bigcirc \\
\text { Low }^{1 \mathrm{~h}, 3}\end{array}$ \\
\hline 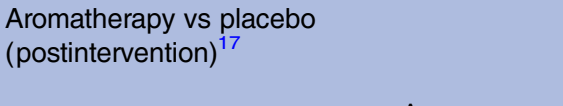 & 1 study (63 participants) & Barthel Scale & $\begin{array}{l}\text { MD }-0.50(-1.79 \text { to } 0.79) \\
\text { Data not available for conversion to } \\
\text { SMD }\end{array}$ & No & $\begin{array}{l}\oplus \oplus \bigcirc \bigcirc \\
\text { Low }^{1 i, 3}\end{array}$ \\
\hline $\begin{array}{l}\text { Nutritional intervention vs control } \\
\text { (postintervention }(3 \text { months }))^{21}\end{array}$ & 3 studies (1262 participants) & Multiple & $\begin{array}{l}\text { Not pooled } \\
\text { The individual trials reported no } \\
\text { significant differences between the } \\
\text { groups }\end{array}$ & No & $\begin{array}{l}\oplus \oplus \oplus \bigcirc \\
\text { Moderate }^{1 j}\end{array}$ \\
\hline \multicolumn{6}{|l|}{ Pharmacological interventions } \\
\hline $\begin{array}{l}\text { Acetylcholinesterase inhibitors and } \\
\text { memantine vs placebo at end point }{ }^{27}\end{array}$ & 12 studies (4661 participants) & $\begin{array}{l}\text { ADCS/ADL } \\
\text { subscale }\end{array}$ & $\begin{array}{l}\text { Donepezil } 5 \mathrm{mg} \text { MD } 1.0(-0.53 \text { to } 2.53) \\
\text { SMD } 0.18(-0.10 \text { to } 0.46) \\
\text { Donepezil } 10 \mathrm{mg} \text { MD } 1.03 \text { (0.21 to } 1.85) \\
\text { SMD } 0.18(0.03 \text { to } 0.32) \\
\text { Galantamine } 24 \mathrm{mg} \mathrm{MD} 0.68(0.04 \text { to } \\
\text { 1.32) SMD } 0.15 \text { (0.04 to } 0.25) \\
\text { Rivastigmine } 12 \mathrm{mg} \mathrm{MD} 1.8(0.20 \text { to } \\
\text { 3.40) SMD } 0.19 \text { (0.02 to } 0.36) \\
\text { Memantine } 20 \mathrm{mg} \mathrm{MD} 1.02(0.27 \text { to } \\
\text { 1.78) SMD } 0.11 \text { (0.02 to } 0.21)\end{array}$ & Yes & $\begin{array}{l}\oplus \oplus \oplus \bigcirc \\
\text { Moderate }^{1 \mathrm{k}}\end{array}$ \\
\hline Latrepirdine vs placebo (postintervention) ${ }^{14}$ & 3 studies (1243 participants) & $\begin{array}{l}\text { ADCS-ADL } \\
\text { Scale }\end{array}$ & $\begin{array}{l}\text { MD } 1.00(-1.15 \text { to } 3.15) \\
\text { SMD } 0.06(-0.06 \text { to } 0.17)\end{array}$ & No & $\begin{array}{l}\oplus \oplus \bigcirc \bigcirc \\
\text { Low }^{11,2}\end{array}$ \\
\hline Melatonin vs placebo $(6 \text { weeks })^{18}$ & 1 study (86 participants) & NI-ADLs & $\begin{array}{l}\mathrm{MD}-2.0(-7.50 \text { to } 3.50) \\
\mathrm{SMD}-0.15(-0.58 \text { to } 0.27)\end{array}$ & No & $\begin{array}{l}\oplus \oplus \oplus \bigcirc \\
\text { Moderate }^{3}\end{array}$ \\
\hline $\begin{array}{l}\text { Pharmacotherapies for sleep vs placebo } \\
\text { (melatonin, trazodone) (postintervention } \\
(2-8 \text { weeks) })^{22}\end{array}$ & 2 studies (193 participants) & Multiple & $\begin{array}{l}\text { Not pooled } \\
\text { The individual trials reported no } \\
\text { significant differences between the } \\
\text { groups }\end{array}$ & No & $\begin{array}{l}\oplus \oplus \oplus \bigcirc \\
\text { Moderate }^{3}\end{array}$ \\
\hline
\end{tabular}

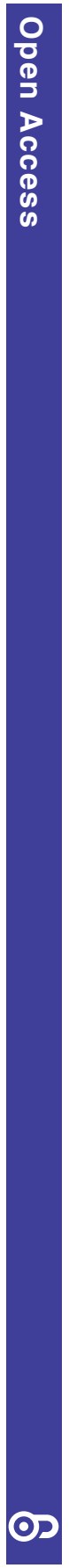

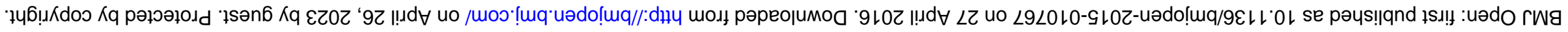


Number of participants included in

Intervention and comparison intervention

Statins vs placebo (3 months) ${ }^{23}$

Selegiline vs placebo $\left(8-17\right.$ weeks) ${ }^{33}$

Nimodipine vs placebo (6 months) ${ }^{34}$

Lecithin vs placebo (6 months) ${ }^{35}$

Alternative therapies

Huperzine A vs placebo (12 weeks) ${ }^{32}$

Gingko biloba vs placebo (endpoint) ${ }^{28}$

Acupuncture vs herbal mixture (8 weeks) $)^{19}$

Vitamins B supplementation vs control

${\text { (postintervention (6-18 months) })^{20}}^{\text {A. Note the nutional interventions inc }}$

3 studies (1109 participants)

7 studies (810 participants)

3 studies (1228 participants)

1 study (63 participants)

2 studies (70 participants)

7 studies (2530 participants)

1 study (104 participants)

3 studies (481 participants) the meta-analysis (studies)
Effect measure (expressed as SMD or MD)

\section{Not pooled}

The individual trials reported no significant differences between the groups SMD 0.27 (95\% Cl 0.13 to 0.41$)$

Multiple

SMD $-0.12(95 \% \mathrm{Cl}-0.23$ to 0.00$)$

Multiple

PADL Scale

The trial reported no significant differences between the groups

ADL Scale

MD $-8.82(-11.47 \text { to }-6.16)^{\mathrm{C}}$

Multiple

SMD $-1.48(-2.02$ to -0.95$)$

Not reported

$E S=0.29$, not significant

Multiple

SMD $0.13(-0.05$ to 0.31$)$
SMD $-0.36(-0.44 \text { to }-0.28)^{\mathrm{D}}$

Statistically

significant

No

Quality of the evidence (GRADE)

A. Note the nutritional interventions included daily oral nutritional supplementation, medical food (Souvenaid) and a health and nutrition promotion programme for physicians, caregivers and people with dementia.

B. Note that the meta-analysis conducted in the systematic review by Ueda and colleagues included randomised and non-randomised trials.

C. The authors report this outcome as an ADL Scale but do not specify the particular scale. A lower score in the meta-analysis was interpreted by the authors as an improvement in ADL

function.

D. The authors reported this reduction in score as an improvement in function. Examination of the meta-analysis suggests that outcome measures were combined. Where outcome measures used higher scores to represent better function, the scores were multiplied by -1 so that all outcome measures were reporting in the same direction in the meta-analysis.

Note: Where MD was reported, the authors of the review calculated the SMD in RevMan.

GRADE footnotes.

${ }^{1}$ Unclear randomisation procedures in three studies. Unclear whether outcome assessor blinded in one study. Participants not blinded. Downgraded for risk of bias.

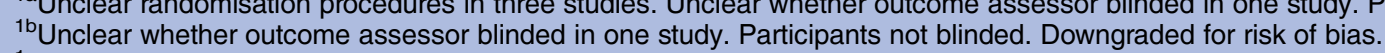

${ }^{10}$ Unclear allocation concealment. Participants not blinded. Downgraded for risk of bias.

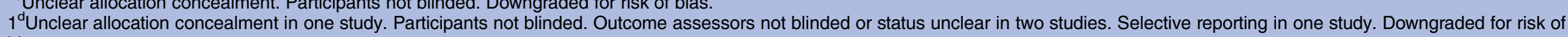
bias.

$1^{\mathrm{e} U n c l e a r}$ allocation concealment and blinding in two studies. Incomplete outcome data in two studies. Participants not blinded. Downgraded for risk of bias.

$1^{f}$ Unclear allocation concealment, randomisation sequence generation, incomplete outcome data and details of blinding in two studies. Downgraded for risk of bias.

$1^{9}$ Randomisation details unclear in all four studies. Details of incomplete outcome data and blinded outcome assessor unclear in single studies ( $\left.\times 2\right)$. Participants not blinded. Downgraded for risk of bias.

$1^{\mathrm{h}}$ Cluster randomisation by care home. Downgraded for risk of bias.

$1^{i}$ Unclear allocation concealment and unclear risk due to incomplete outcome data. Downgraded for risk of bias.

$1^{\mathrm{j} T}$ Two of the three studies were rated as being of moderate quality while the remaining study was rated as strong. Downgraded for risk of bias.

$1^{\mathrm{k}}$ Mixed quality of studies and variability in transparency of reporting. Downgraded for risk of bias.

$1^{\prime}$ High risk of bias for incomplete outcome data and selective reporting in two studies. Unclear allocation concealment in one study. Downgraded for risk of bias.

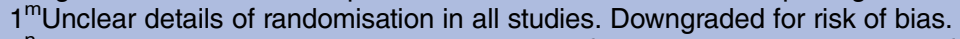

$1^{\text {n }}$ Unclear selective reporting and unclear risk of bias in other areas reported for one study. Downgraded for risk of bias.

${ }^{2}$ Mixed findings among studies, Cls do not overlap. Downgraded for inconsistency.

${ }^{3}$ Total number of participants $<400$ in the analyses. Downgraded for imprecision.

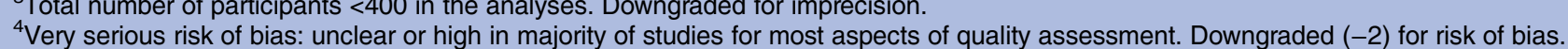

${ }^{4}$ Very serious risk of bias: unclear or high in majority of studies for most aspects of quality assessment. Downgraded (-2) for risk of bias.
ADCS, Alzheimer's disease co-operative study; ADL, activities of daily living; ES, effect size; NI-ADL, nurse informant activities of daily living; PADL, physical ADL; SMD, standardised mean

difference; MD, mean difference. 
The interventions that were found to have a significant effect on ADL function should not be difficult to implement routinely for people with dementia as they are accessible in most Western countries. However, health professionals should note that the non-pharmacological interventions that were effective (exercise and dyadic interventions) involved regular participation. Exercise programmes ranged in frequency from 2 to 5 times per week and were programmed over a minimum of 7 weeks. Dyadic interventions were scheduled over a number of treatment sessions. It should be noted that the interventions reduced functional decline relative to the control group rather than leading to improvements in functional performance compared with the baseline, indicating a slowing of functional decline rather than prevention.

The number of research trials evaluating the efficacy of acetylcholinesterase inhibitors is large relative to research conducted in other aspects of dementia treatment. Published studies consistently demonstrate a positive effect on cognition and ADL function. Clinicians need to consider the potential bias of the research in this field given that many of the studies were funded by pharmaceutical companies. Killin et a $\tilde{l}^{4}$ conducted a meta-analysis examining the differences in findings between industry-funded and independent RCTs of donepezil and found that studies sponsored by pharmaceutical companies reported a larger effect on standardised cognitive tests than independent research groups.

Policymakers should consider the results of this review and implications for practice. For example, in Australia, while the government spends a large amount of money subsidising acetylcholinesterase inhibitors and memantine (over $\$ 60$ million per year ${ }^{55}$ ), there is less money invested in ensuring people with dementia can access appropriate exercise programmes or dyadic interventions, which may be associated with other benefits such as improved cardiovascular health, reduced carer burden and increased community participation.

The benefit of conducting an overview is that it provides a wide-ranging perspective on the intervention approaches available and their relative efficacy. One of the limitations of this approach is that the most recently published primary studies are not captured. However, the search dates of the included reviews were relatively recent in most cases. Furthermore, while the body of research for interventions in dementia care is slowly accumulating, there have not been any significant advances in the past couple of years that would alter routine care. Another limitation is that systematic reviews tend to examine single-intervention approaches and therefore more complex multifactorial interventions (eg, physical exercise plus cognitive stimulation) have not been captured. In addition, the detail of participants, intervention and results are less prominent at the level of overview and there is a little scope to delve into the details of the individual interventions. The findings of this review suggest that clinicians should familiarise themselves with the details of the type of exercise and dyadic interventions thought to be most effective. ${ }^{16} 30$

This particular overview did not seek to identify additional trials that may have been missed in the 'included' systematic review and excluded reviews in languages published other than English. Furthermore, we only included RCTs which restricted the number of studies included and information that can be drawn upon. The results of this overview highlight effective approaches but do not provide much needed information around cost-effectiveness as economic evaluations in dementia care are scarce..$^{56}$

There is clearly more work to be performed in both developing interventions to delay functional decline and testing interventions to provide more evidence around the type of approaches that are most effective and for whom. For example, the review on exercise failed to provide recommendations about the type of exercise or population most likely to benefit due to the heterogeneity of studies.

In conclusion, at the current time in the absence of disease-modifying treatments for dementia, health professionals should attempt to minimise functional decline in people with dementia by considering prescription of acetylcholinesterase inhibitors and memantine, and recommending exercise and dyadic interventions.

Acknowledgements The authors thank Dr Enwu Liu for creating the graphic (figure 2).

Contributors $\mathrm{KL}$ and SD were responsible for conceptualising the design of the study, identifying the included reviews and drafting the results. CW, LC and $\mathrm{MC}$ were responsible for interpreting the data and revising the work for important intellectual content. All authors approve this version for publication and are accountable for the content of the work.

Funding This work was supported by the National Health and Medical Research Council (NHMRC) Partnership Centre on Dealing with Cognitive and Related Functional Decline in Older People (grant no. GNT9100000).

Competing interests All authors have completed the ICMJE uniform disclosure form at http://www.icmje.org/coi_disclosure.pdf and declare this research was supported by grant funding from the National Health and Medical Research Council Partnership Centre on Dealing with Cognitive and Related Functional Decline in Older People (grant no. GNT9100000). KL, CW, $\mathrm{LC}$ and MC have received research grants from government agencies, charitable foundations or academic institutions which have not influenced the submitted work. All authors have been involved in developing clinical practice guidelines for dementia in Australia.

Provenance and peer review Not commissioned; externally peer reviewed.

Data sharing statement No additional data are available.

Open Access This is an Open Access article distributed in accordance with the Creative Commons Attribution Non Commercial (CC BY-NC 4.0) license, which permits others to distribute, remix, adapt, build upon this work noncommercially, and license their derivative works on different terms, provided the original work is properly cited and the use is non-commercial. See: http:// creativecommons.org/licenses/by-nc/4.0/

\section{REFERENCES}

1. Prince $M$, Bryce $R$, Albanese $E$, et al. The global prevalence of dementia: a systematic review and metaanalysis. Alzheimers Dement 2013;9:63-75.e2.

2. Prince M, Guerchet M, Prina M, et al. Policy briefs for heads of government: the global impact of dementia 2013-2050. London: Alzheimer's Disease International 2013. 
3. Andersen CK, Wittrup-Jensen KU, Lolk A, et al. Ability to perform activities of daily living is the main factor affecting quality of life in patients with dementia. Health Qual Life Outcomes 2004;2:52.

4. Gustavsson A, Brinck P, Bergvall N, et al. Predictors of costs of care in Alzheimer's disease: a multinational sample of 1222 patients. Alzheimers Dement 2011;7:318-27.

5. Brodaty $\mathrm{H}$, Woodward $\mathrm{M}$, Boundy $\mathrm{K}$, et al. Prevalence and predictors of burden in caregivers of people with dementia. Am J Geriatr Psychiatry 2014;22:756-65.

6. Brodaty H, Seeher K, Gibson L. Dementia time to death: a systematic literature review on survival time and years of life lost in people with dementia. Int Psychogeriatr 2012;24:1034-45.

7. Kurrle S, Brodaty H, Hogarth R. Physical comorbidities of dementia. Cambridge University Press, 2012.

8. Alzheimer's Australia. Report for the Department of Health and Ageing in relation to services for Consumer Engagement in the Aged Care Reform Process. Canberra, 2011.

9. Higgins J, Green S. Cochrane handbook for systematic reviews of interventions version 5.1. 0 [updated March 2011]. The Cochrane Collaboration, 2011.

10. NHS Centre for Reviews and Dissemination. Undertaking systematic reviews of research on effectiveness. CRD's guidance for those carrying out or commissioning reviews. 2nd edn. Centre for Reviews and Dissemination, 2001.

11. Shea BJ, Grimshaw JM, Wells GA, et al. Development of AMSTAR: a measurement tool to assess the methodological quality of systematic reviews. BMC Med Res Methodol 2007;7:10.

12. Guyatt $\mathrm{GH}$, Oxman AD, Vist GE, et al. GRADE: an emerging consensus on rating quality of evidence and strength of recommendations. BMJ 2008;336:924-6.

13. Bahar-Fuchs A, Clare L, Woods B. Cognitive training and cognitive rehabilitation for mild to moderate Alzheimer's disease and vascular dementia. Cochrane Database Syst Rev 2013;6:CD003260.

14. Chau S, Herrmann N, Ruthirakuhan MT, et al. Latrepirdine for Alzheimer's disease. Cochrane Database Syst Rev 2015;4 CD009524.

15. Forbes D, Blake CM, Thiessen EJ, et al. Light therapy for improving cognition, activities of daily living, sleep, challenging behaviour, and psychiatric disturbances in dementia. Cochrane Database Syst Rev 2014;2:CD003946.

16. Forbes D, Thiessen EJ, Blake CM, et al. Exercise programs for people with dementia. Cochrane Database Syst Rev 2013;12: CD006489.

17. Forrester LT, Maayan N, Orrell M, et al. Aromatherapy for dementia. Cochrane Database Syst Rev 2014;2:CD003150.

18. Jansen SL, Forbes DA, Duncan V, et al. Melatonin for cognitive impairment Cochrane Database Syst Rev 2006;(1):CD003802.

19. Lee MS, Shin BC, Ernst E. Acupuncture for Alzheimer's disease: a systematic review. Int J Clin Pract 2009;63:874-9.

20. Li M-M, Yu J-T, Wang H-F, et al. Efficacy of vitamins $B$ supplementation on mild cognitive impairment and Alzheimer's disease: a systematic review and meta-analysis. Curr Alzheimer Res 2014;11:844-52.

21. Liu W, Cheon J, Thomas SA. Interventions on mealtime difficulties in older adults with dementia: a systematic review. Int J Nurs Stud 2014;51:14-27.

22. McCleery J, Cohen DA, Sharpley AL. Pharmacotherapies for sleep disturbances in Alzheimer's disease. Cochrane Database Syst Rev 2014;3:CD009178

23. McGuinness B, Craig D, Bullock R, et al. Statins for the treatment of dementia. Cochrane Database Syst Rev 2014;7:CD007514.

24. Neal M, Barton Wright P. Validation therapy for dementia. Cochrane Database Syst Rev 2009;(3):CD001394.

25. Orgeta V, Qazi A, Spector AE, et al. Psychological treatments for depression and anxiety in dementia and mild cognitive impairment Cochrane Database Syst Rev 2014;1:CD009125.

26. Reilly S, Miranda-Castillo C, Malouf R, et al. Case management approaches to home support for people with dementia. Cochrane Database Syst Rev 2015;1:CD008345.

27. Tan C-C, Yu J-T, Wang H-F, et al. Efficacy and safety of donepezil, galantamine, rivastigmine, and memantine for the treatment of Alzheimer's disease: a systematic review and meta-analysis. J Alzheimers Dis 2014;41:615-31.

28. Tan MS, Yu JT, Tan CC, et al. Efficacy and adverse effects of Ginkgo biloba for cognitive impairment and dementia: a systematic review and meta-analysis. J Alzheimers Dis 2015;43:589-603.

29. Ueda T, Suzukamo Y, Sato M, et al. Effects of music therapy on behavioral and psychological symptoms of dementia: a systematic review and meta-analysis. Ageing Res Rev 2013;12:628-41.
30. Van't Leven N, Prick AEJ, Groenewoud JG, et al. Dyadic interventions for community-dwelling people with dementia and their family caregivers: a systematic review. Int Psychogeriatr 2013;25:1581-603.

31. Woods B, Aguirre E, Spector AE, et al. Cognitive stimulation to improve cognitive functioning in people with dementia. Cochrane Database Syst Rev 2012;2:CD005562.

32. Yang G, Wang Y, Tian J, et al. Huperzine A for Alzheimer's disease: a systematic review and meta-analysis of randomized clinical trials. PLOS ONE 2013;8:e74916.

33. Birks J, Flicker L. Selegiline for Alzheimer's disease. Cochrane Database Syst Rev 2003;(1):CD000442.

34. Birks J, Lopez-Arrieta JM. Nimodipine for primary degenerative, mixed and vascular dementia. Cochrane Database Syst Rev 2002; (3):CD000147.

35. Higgins JP, Flicker L. Lecithin for dementia and cognitive impairment. Cochrane Database Syst Rev 2003;(3):CD001015.

36. Bemelmans R, Gelderblom GJ, Jonker P, et al. Socially assistive robots in elderly care: a systematic review into effects and effectiveness. J Am Med Dir Assoc 2012;13:114-20.e1.

37. Bernabei V, De Ronchi D, La Ferla T, et al. Animal-assisted interventions for elderly patients affected by dementia or psychiatric disorders: a review. J Psychiatr Res 2013;47:762-73.

38. Cameron M, Lonergan E, Lee $\mathrm{H}$. Transcutaneous electrical nerve stimulation (TENS) for dementia. Cochrane Database Syst Rev 2003;(3):CD004032.

39. Leung $P$, Orrell $M$, Orgeta V. Social support group interventions in people with dementia and mild cognitive impairment: a systematic review of the literature. Int J Geriatr Psychiatry 2015;30:1-9.

40. Lu D, Song H, Hao Z, et al. Naftidrofuryl for dementia. Cochrane Database Syst Rev 2011;(12):CD002955.

41. Maayan N, Soares-Weiser K, Lee H. Respite care for people with dementia and their carers. Cochrane Database Syst Rev 2014;1: CD004396.

42. Martin S, Kelly G, Kernohan WG, et al. Smart home technologies for health and social care support. Cochrane Database Syst Rev 2008; (4):CD006412.

43. Sampson EL, Jenagaratnam L, McShane R. Metal protein attenuating compounds for the treatment of Alzheimer's dementia. Cochrane Database Syst Rev 2014;2:CD005380.

44. Tabet N, Feldmand H. Ibuprofen for Alzheimer's disease. Cochrane Database Syst Rev 2003;(2):CD004031.

45. Thompson CA, Spilsbury K, Hall J, et al. Systematic review of information and support interventions for caregivers of people with dementia. BMC Geriatr 2007;7:18.

46. Lopez-Arrieta JM, Schneider L. Metrifonate for Alzheimer's disease. Cochrane Database Syst Rev 2006;(2):CD003155.

47. Hopper T, Bourgeois M, Pimentel J, et al. An evidence-based systematic review on cognitive interventions for individuals with dementia. Am J Speech Lang Pathol 2013;22:126-45.

48. Carrion C, Aymerich M, Bailles E, et al. Cognitive psychosocial intervention in dementia: a systematic review. Dement Geriatr Cogn Disord 2013;36:363-75.

49. Zhu XC, Yu Y, Wang HF, et al. Physiotherapy intervention in Alzheimer's disease: systematic review and meta-analysis. $J$ Alzheimers Dis 2015;44:163-74.

50. Rao AK, Chou A, Bursley B, et al. Systematic review of the effects of exercise on activities of daily living in people with Alzheimer's disease. Am J Occup Ther 2014;68:50-6.

51. Cohen J. Statistical power analysis for the behavioral sciences Lawrence Erlbaum Associates, Inc. 1977.

52. Cooper C, Mukadam N, Katona C, et al. Systematic review of the effectiveness of non-pharmacological interventions to improve quality of life of people with dementia. Int Psychogeriatr 2012;24:856-70.

53. Cooper C, Mukadam N, Katona C, et al. Systematic review of the effectiveness of pharmacologic interventions to improve quality of life and well-being in people with dementia. Am J Geriatr Psychiatry 2013;21:173-83.

54. Killin LO, Russ TC, Starr JM, et al. The effect of funding sources on donepezil randomised controlled trial outcome: a meta-analysis. BMJ Open 2014;4:e004083.

55. Centre for Health Economics Monash University, University of South Australia Veterans' Medicines Advice and Therapeutics Education Services. Post Market Review Pharmaceutical Benefits Scheme anti-dementia medicines to treat Alzheimer's Disease. 2012. http://www.pbs.gov.au/reviews/anti-dementia-drugs-files/antidementia-report-summary.pdf

56. Knapp M, lemmi V, Romeo R. Dementia care costs and outcomes: a systematic review. Int J Geriatr Psychiatry 2013;28:551-61. 